Institute of $\mathbf{F}_{\text {ood and }} \mathbf{A}_{\text {gricultural }} \mathbf{S}_{\text {ciences }}$

\title{
2003 Handbook of Employment Regulations Affecting Florida Farm Employers and Workers: Transportation -- Alcohol and Drug Testing [Federal] ${ }^{1}$
} \author{
accidents and injuries resulting from the misuse of \\ alcohol or use of controlled substances by drivers of \\ commercial motor vehicles.
}

Leo C. Polopolus, Michael T. Olexa, Fritz Roka, and Carol Fountain ${ }^{2}$
- Employers not subject to this law's requirements will be those few employers who exclusively employ drivers who are not subject to the CDL's requirements (e.g., farmers who employ drivers who have been waived of CDL requirements).

\section{Definitions}

- Employer is defined as any person who owns or leases a commercial motor vehicle or assigns persons to operate such a vehicle. The term employer includes an employer's agents, officers, or representatives. (Thus, growers who employ farm labor contractors who, in turn, employ operators of CMVs with CDLs may be liable to ensure that drivers are properly tested.)
- Thus, individuals employed within agriculture who drive a CMV and are required to possess a

$\mathrm{CDL}$ are covered under the program.

- This federal program requires that all drivers of commercial motor vehicles (CMV) who are required to obtain a Commercial Driver's License (CDL) be tested for illegal use of alcohol and controlled substances. .

(n)

\section{Who Must Comply}

\footnotetext{
1. This is EDIS document FE416, a publication of the Department of Food and Resource Economics, Florida Cooperative Extension Service, Institute of Food and Agricultural Sciences, University of Florida, Gainesville, FL. Published July 2003. This information is included in Circular 1200, Handbook of Employment Regulations Affecting Florida Farm Employers and Workers. First published February 1992 as Circular 1043 . Revised December 2002 as Circular 1200. Please visit the EDIS website at http://edis.ifas.ufl.edu.

2. Leo C. Polopolus, Professor Emeritus, Department of Food and Resource Economics, University of Florida, Gainesville, FL; Michael T. Olexa, Professor, Department of Food and Resource Economics, University of Florida, Gainesville, FL; Fritz Roka, Associate Professor, Department of Food and Resource Economics, Southwest Florida Research and Education Center, Immokalee, FL; and Carol Fountain, Assistant Editor, Department of Food and Resource Economics, University of Florida, Gainesville, FL; Florida Cooperative Extension Service, Institute of Food and Agricultural Sciences, University of Florida, Gainesville, FL.

This document is designed to provide accurate, current, and authoritative information on the subject. However, since the laws, administrative rulings, and court decisions on which it is based are subject to constant revision, portions of this publication could become outdated at any time. This publication is distributed with the understanding that the authors are not engaged in rendering legal or other professional advice, and the information contained herein should not be regarded as a substitute for professional advice. For these reasons, the utilization of these materials by any person constitutes an agreement to hold harmless the authors, the Institute of Food and Agricultural Sciences, and the University of Florida for any liability claims, damages, or expenses that may be incurred by any person as a result of reference to or reliance on the information contained in this publication.
}

The Institute of Food and Agricultural Sciences is an equal opportunity/affirmative action employer authorized to provide research, educational information and other services only to individuals and institutions that function without regard to race, color, sex, age, handicap, or national origin. For information on obtaining other extension publications, contact your county Cooperative Extension Service office. Florida Cooperative Extension Service/Institute of Food and Agricultural Sciences/University of Florida/Christine Taylor Waddill, Dean. 
- Alcohol means the intoxicating agent in beverage alcohol, ethyl alcohol, or other low molecular weight alcohols, including methyl and isopropyl alcohol.

- Commercial motor vehicle means a motor vehicle used in commerce to transport passengers or property of the motor vehicle which meets one of the following requirements:

- Has a gross combination weight rating of 26,001 or more pounds inclusive of a towed unit with a gross vehicle weight rating of more than 10,000 pounds.

- Has a gross vehicle weight rating of 26,001 or more pounds.

- Is designed to transport sixteen or more passengers, including the driver.

- Is of any size and is used in the transportation of hazardous materials.

- Confirmation test for alcohol testing means a second test, following a screening test, with a result of 0.02 or greater of alcohol concentration.

- Screening test (also known as initial test) means an analytical procedure (in alcohol testing) to determine whether a driver may have a prohibited concentration of alcohol in his or her system.

\section{Driver / Employer Prohibitions}

- No driver shall report for duty or remain on duty while having an alcohol concentration of 0.04 or greater. Also, no employer having actual knowledge that a driver has an alcohol concentration of 0.04 or greater shall permit the driver to perform or continue to perform safety-sensitive functions.

- No driver shall be on duty or operate a commercial motor vehicle while the driver possesses alcohol, unless the alcohol is manifested and transported as part of a shipment. Also, no employer having actual knowledge that a driver possesses unmanifested alcohol may permit the driver to drive a CMV.
- No driver shall use alcohol while performing safety-sensitive functions. Also, no employer having actual knowledge that a driver is using alcohol while performing safety-sensitive functions shall permit the driver to perform safety-sensitive functions.

- No driver shall perform safety-sensitive functions within four hours after using alcohol. No employer having actual knowledge that such a driver has used alcohol within four hours shall permit a driver to perform safety-sensitive functions.

- No driver required to take a post-accident alcohol test shall use alcohol for eight hours following the accident or until he or she undergoes a post-accident test, whichever occurs first.

- No driver shall refuse to submit to a post-accident alcohol or controlled substances test. Also, no employer shall permit a driver who refuses to submit to such tests to perform safety-sensitive functions.

- No driver shall report for duty or remain on duty when the driver uses any controlled substance, except when the use is pursuant to the instructions of a physician who has advised the driver that the substance does not adversely affect the driver's ability to safely operate a CMV. Also, no employer having actual knowledge that a driver has used a controlled substance shall permit the driver to perform safety-sensitive functions. (The employer may require the driver to inform the employer of any therapeutic drug use.)

- No driver shall report for duty, remain on duty, or perform a safety-sensitive function if the driver tests positive for controlled substances. Also, no employer, having actual knowledge that a driver has tested positive for controlled substances, shall permit the driver to perform safety-sensitive functions. 


\section{Tests Required}

\section{Pre-Employment Testing}

- An employer is not required to administer an alcohol test at pre-employment if the driver has undergone an alcohol test within the previous six months with a result indicating a concentration of less than 0.04 and the employer ensures that no prior employer of the driver has knowledge nor records of a violation of the regulations within the previous six months.

- Regarding controlled substances, the employer is not required to administer a pre-employment test if the driver participated in a drug-testing program and met regulation requirements within the previous thirty days. Also, the employer must ensure that no prior employer of the driver of whom the employer has knowledge has records of a violation of regulations within the previous six months.

- Any employer who chooses to employ the exception for pre-employment alcohol or controlled substance testing must obtain the following information:

- Name and address of testing program used previously by the driver.

- Verification that the driver participated in the program.

- Verification that the program conformed to the regulations.

- Verification that the driver is qualified under the regulations.

- Date the driver was last tested.

- Results of any tests taken within the previous six months and any violations of the federal regulations.

- An employer who uses but does not employ a driver more than once a year must make assurances once every six months that the driver participates in an alcohol and controlled substance program.

\section{Post-Accident Testing}

- As soon as practicable following an accident involving a CMV, each employer shall test for alcohol and controlled substances for each surviving driver:

-Who was performing safety-sensitive functions where the accident involved the loss of human life.

- Who received a citation under state or local law for a moving traffic violation arising from the accident.

- If an alcohol test is not administered within two hours following the accident, the employer shall prepare and maintain a file record stating reasons why the test was not promptly administered.

- If a controlled substance test is not administered within thirty-six hours following the accident, the employer must attempt to administer a controlled substance test and prepare and maintain on file a record stating the reasons why the test was not promptly administered.

- An employer is required to provide drivers with the necessary post-accident information procedures and instructions prior to the driver operating a CMV so that drivers will be informed regarding testing requirements.

- A driver who is subject to post-accident testing must remain readily available for testing or may be deemed by the employer to have refused to submit to testing.

- The results of a breath or blood test for the use of alcohol or a urine test for the use of controlled substances conducted by federal, state, or local officials will be considered to meet the requirements of the regulations provided such tests conform to applicable federal, state, or local requirements and that the results of the tests are obtained by the employer. 


\section{Random Testing}

- The minimum annual percentage rate for random alcohol testing is twenty-five percent of the average number of driver positions.

- The minimum annual percentage rate for random controlled substance testing is fifty percent of the average number of driver positions.

- The selection of drivers for random alcohol and controlled substance testing may be made by a scientifically valid method such as a random number table or a computer-based random number generator that is matched with a driver's social security number or payroll ID number. Whatever method is used, each driver must have an equal chance of being tested each time selections are made.

- The employer must require that each driver who is notified of selection for random testing proceeds to the test site immediately.

- A driver may only be tested for alcohol while he or she is performing safety-sensitive functions just before the driver is to perform safety-sensitive functions or just after the driver has ceased performing such functions.

\section{Reasonable Suspicion Testing}

- An employer must require a driver to submit to alcohol and/or controlled substance tests when the employer has reasonable suspicion to believe that the driver has violated the prohibition of this regulation, except for merely possessing alcohol.

- The driver may be directed to only undergo reasonable suspicion testing while the driver is performing safety-sensitive functions just before the driver is to perform safety-sensitive functions or just after the driver has ceased performing such functions.

\section{Return to Duty Testing}

- The employer must ensure that, before a driver returns to duty after engaging in conduct prohibited by regulations concerning alcohol, the driver must undergo a return-to-duty alcohol test with a result indicating a concentration of less than 0.02 .

- The employer must also ensure that before a driver returns to duty after engaging in conduct prohibited by regulations concerning controlled substances, the driver must undergo a return-to-duty controlled substance test with a result indicating a verified negative for controlled substance abuse.

\section{Follow-Up Testing}

- Following determination that a driver is in need of assistance in resolving problems associated with alcohol misuse and/or use of controlled substances, the employer must ensure that the driver is subject to unannounced follow-up testing as directed by a substance abuse professional.

- Follow-up alcohol testing may only be conducted immediately before, during or immediately after the driver performs safety-sensitive functions.

\section{Handling of Test Results and Record Retention}

- Every affected employer must maintain records of its alcohol misuse and controlled substance use prevention programs.

- The records must be maintained in a secure location with controlled access.

- The following records must be maintained by the employer for a period of five years:

- Driver alcohol test results for 0.02 or greater alcohol concentrations.

- Records of driver verified positive controlled substance test results.

- Documentation of refusals to take required tests.

- Calibration documentation. 
- A copy of each annual calendar year summary.

- Records related to the alcohol and controlled substance collection process and training must be maintained for a minimum of two years.

- Records of negative and cancelled controlled substance test results and alcohol test results with a concentration of less than 0.02 must be maintained for a minimum of one year.

\section{Reporting of Results}

- All employers covered by this regulation must prepare and maintain an annual calendar year summary of the results of alcohol and controlled substance testing programs.

- Each annual calendar year summary containing information on a verified positive controlled substance test result, alcohol screening test result of 0.02 of greater, or any other violation of the alcohol misuse requirements must include specified information on the number of drivers, number of urine specimens collected by type of test, number and type of positive tests for controlled substances, etc.

-Where an employer's annual calendar year summary contains only negative controlled substance abuse test results, alcohol screening test results of less than 0.02 and no other violations, an EZ report form may be submitted.

\section{Access to Facilities and Records}

- No employer may release driver information required by this regulation.

- A driver, however, is entitled, upon written request, to obtain copies of records pertaining to the driver's use of alcohol or controlled substances, including any records pertaining to the driver's alcohol or controlled substance tests.

\section{Medical Review Officer Notification}

- All tests must be reviewed by a Medical Review Officer (MRO). A signed, written notification must be forwarded within three business days of completion of the MRO's review.

- No person may obtain the individual controlled substance test results of any driver without first obtaining a specific written authorization from the tested driver.

- The MRO is not prohibited from releasing the test results to the employer or to officials of the U.S. Secretary of Transportation, any DOT agency, or any state or local officials with regulatory authority over the controlled substance testing program.

\section{Employer Notification}

- The employer must notify a driver of the results of a pre-employment controlled substance test if the driver requests the results within sixty calendar days of being notified of the disposition of the employment application.

- Employers must also notify a driver of the results of random, reasonable suspicion and post-accident tests for controlled substance if test results are verified positive. In addition, the employer must inform the driver which controlled substances were verified positive.

\section{Information, Training, and Referral}

- Each affected employer must provide educational materials that explain the requirements of the alcohol and drug testing program, plus the employer's policies and procedures for fulfilling these requirements.

- Employers must ensure that copies of the educational materials are distributed to each driver prior to the start of alcohol and controlled substance testing and to each driver subsequently hired or transferred into a position of driving a CMV.

- Employers must ensure that their staff who determine whether reasonable suspicion exists (who subject drivers to testing) receive at least 
sixty minutes of training on alcohol misuse and receive an additional sixty minutes of training on controlled substance use.

- The training must cover the physical, behavioral, speech, and performance indicators of probable alcohol misuse and use of controlled substances.

- Each driver who has engaged in prohibited conduct must be advised by the employer of the resources available to the driver in evaluating and resolving problems associated with the measure of alcohol and use of controlled substances.

- Before a driver returns to duty after engaging in prohibited conduct, the driver must undergo a return-to-duty alcohol test with a test result less than 0.02 or a verified negative result on the controlled substance test.

- Each driver identified as needing assistance in resolving problems associated with alcohol abuse or controlled substance use must be evaluated by a substance abuse professional to determine that the driver has properly followed any rehabilitation program prescribed and will be subject to unannounced follow-up alcohol and control substance tests administered by the employer following the driver's return to duty.

- Evaluation and rehabilitation may be provided by the employer, by a substance abuse professional affiliated with the employer, or by a substance abuse professional unaffiliated with the employer.

\section{Related Information}

- Controlled Substances and Alcohol Use and Testing, C.F.R., Title 49, Chapter III, Part 382, U.S. Department of Transportation, Federal Highway Administration, Bureau of Motor Carrier Safety.

\section{Responsible Agency}

\section{U.S. Department of Transportation}

Federal Highway Administration

Office of Motor Carrier Safety

61 Forsyth Street SW, Suite $17 \mathrm{T75}$

Atlanta, GA 30367

(404) $562-3600$

http://www.fmcsa.dot.gov/aboutus/aboutus.htm 